\title{
Evolution and Challenges of Irrigation and Drainage Engineering Research
}

\section{Luciano Mateos*}

Institute for Sustainable Agriculture, CSIC. Cordova, Spain

The evolution of irrigation engineering during the last 50 years may be synthesized as the progressive improvement of application uniformity. Drip irrigation, laser leveling for surface irrigation, and the new generations of sprinklers and traveling sprinkler machines have enhanced application uniformity and, as a consequence, irrigation efficiency and adequacy. The fraction of the irrigation water that is consumed by the crops, and therefore that contributes to yield, has increased dramatically. Regulated deficit irrigation and site-specific variable rate sprinkler irrigation are novel techniques that could push the irrigation forefront a little bit further; however, the room for improvement is very small already. Irrigation engineering seems to be dying from success.

However, there are new irrigation challenges that call for new irrigation research paradigms. While food security in many of the poorest regions in the world relies on irrigated agriculture, the irrigation performance and crop yield gaps are enormous. Furthermore, the expansion and intensification of irrigation are causing serious environmental problems such as the pollution of valuable ecosystems and the overdraft of non-renewable groundwater.

Irrigation and drainage engineers will need to join multidisciplinary teams in order to boost our understanding of the interconnected facets (sociological, political, environmental, hydrological...) of irrigation and launch a renewed irrigation research and development strategy. The open access Irrigation \& Drainage Systems Engineering Journal is an ideal forum where irrigation researchers, professionals, and practitioners will be able to discuss the new challenging irrigation issues worldwide.
${ }^{*}$ Corresponding author: Luciano Mateos, Institute for Sustainable Agriculture, CSIC, Cordova, Spain, E-mail: ag1mainl@uco.es

Received November 22, 2012; Accepted November 22, 2012; Published November 26, 2012

Citation: Mateos L (2012) Evolution and Challenges of Irrigation and Drainage Engineering Research. Irrigat Drainage Sys Eng 1:e112. doi:10.4172/21689768.1000e112

Copyright: (c) 2012 Mateos L. This is an open-access article distributed under the terms of the Creative Commons Attribution License, which permits unrestricted use, distribution, and reproduction in any medium, provided the original author and source are credited. 